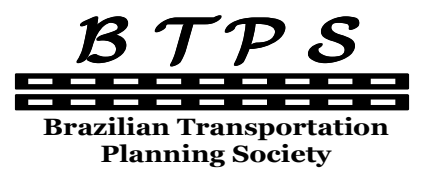

Planning Society
Journal of Transport Literature

Vol. 6, n. 4, pp. 82-100, Oct 2012

Research Directory
JTL | RELIT

www.transport-literature.org ISSN 2238-1031

\title{
Liberalização econômica e universalização do acesso no transporte aéreo: é possível conciliar livre mercado com metas sociais e ainda evitar gargalos de infraestrutura
}

\author{
[Economic liberalization and universal access in air transport: the free market can be reconciled with \\ social goals and still avoid infrastructure bottlenecks] \\ Nara Zimmermann*, Alessandro V. M. Oliveira \\ Instituto Tecnológico de Aeronáutica (ITA), Brazil
}

Submitted 10 Jul 2011; received in revised form 12 Dec 2011; accepted 26 Jan 2012

\begin{abstract}
Resumo
A liberalização econômica do transporte aéreo brasileiro trouxe visíveis benefícios ao setor, com preços mais baixos e maior popularização. Houve, entretanto, mais concentração da operação em grandes aeroportos e perda de cobertura regional. 0 presente trabalho tem por objetivo analisar a evolução do número de aeroportos servidos pelo transporte aéreo regular brasileiro, bem como os índices de concentração de operações e a cobertura ao longo do território nacional. Serão abordados aspectos contidos no processo de desregulação econômica que o mercado aéreo brasileiro sofreu nos anos 1990 e início dos anos 2000, fazendo com que o transporte aéreo nacional passasse a ser mais competitivo e eficiente, mas também com operação mais concentrada geograficamente. Estes fatores acarretaram benefícios e malefícios aos passageiros: por um lado, preços mais baixos, alta indução do tráfego aéreo e maior acessibilidade de novos segmentos de consumidores; por outro, crescimento acelerado pressionado das infraestruturas aeroportuária e do espaço aéreo - com decorrentes gargalos geradores de congestionamentos e atrasos - e piora na cobertura geográfica. Este estudo desenvolveu um modelo econométrico que possibilitou análise de potenciais variáveis explicativas da cobertura do transporte aéreo, bem como sua influência e impacto no número de aeroportos servidos.
\end{abstract}

Palavras-Chave: desregulamentação; número de aeroportos; transporte aéreo; econometria.

\begin{abstract}
The economic liberalization of the Brazilian air transportation has brought visible benefits to the sector, with lower prices and greater popularity. There was, however, more concentration of the operation at major airports and loss of regional coverage. This paper aims to analyze the development of the number of airports served by regular air transportation in Brazil, as well as the concentration indices of operations and coverage across the national territory. It will examine aspects from the process of economic deregulation that the Brazilian air market suffered in the 1990s and early 2000s, causing the national air transportation became more competitive and efficient, but also with operate more geographically concentrated. These factors resulted in benefits and in harms to passengers: on the one hand, lower prices, high induction air traffic's and increased accessibility of new customer, on the other hand, pressed accelerated growth of airport infrastructure and airspace - with arising congestion generators bottlenecks and delays - and worst coverage. This study developed an econometric model that allowed for analysis of potential explanatory variables of the coverage of air transport as well as their influence and impact on the number of airports served.
\end{abstract}

Key words: deregulation; number of airports; airline market; econometrics.

* Corresponding Author. Email: narabianca@yahoo.com.br.

\section{Recommended Citation}

Zimmermann, N. and Oliveira, A. V. M. (2012) Liberalização econômica e universalização do acesso no transporte aéreo: é possível conciliar livre mercado com metas sociais e ainda evitar gargalos de infraestrutura. Journal of Transport Literature, vol. 6, n. 4, pp. 82-100.

- JTL/RELIT is a fully electronic, peer-reviewed, open access, international journal focused on emerging transport markets and published by BPTS - Brazilian Transport Planning Society. Website www.transport-literature.org. ISSN 2238-1031.

This paper is downloadable at www.transport-literature.org/open-access. 


\section{Introdução}

Este trabalho consiste na realização de um estudo da evolução do número de aeroportos no território brasileiro, visando apresentar tendências da política regulatória e de relevantes indicadores sociais e de mercado do segmento do transporte aéreo brasileiro. Inicia com uma análise da última grande reforma regulatória a que foi submetido o setor - a chamada Política de Flexibilização da Aviação Comercial, criada nos anos 1990. Esta política teve o objetivo de promover uma maior liberalização do mercado, com estímulo à competitividade visando induzir ganhos de bem-estar econômico ao consumidor. Busca, assim, descrever a evolução das políticas setoriais, marcadas pelos princípios liberalizantes estabelecidos na lei de constituição da Agência Nacional de Aviação Civil, ANAC (Lei n. 11.182, conforme Salgado 2008).

Como consequência de duas décadas de medidas de liberalização econômica, o País possui hoje um transporte aéreo mais competitivo e eficiente, mas também com operação mais concentrada em poucos aeroportos e regiões; estes fatores acarretaram benefícios e malefícios aos passageiros e que devem ser ponderados com vistas à constituição de um marco regulatório renovado para o setor: por um lado, com preços mais baixos, tem havido altíssima indução de tráfego aéreo e razoável incremento na acessibilidade de novos segmentos de consumidores - o que gerou um aumento na popularização, ou maior "universalização" do setor nos grandes centros. Por outro, o crescimento acelerado gerou pressões sobre as infraestruturas aeroportuária e de espaço aéreo - e estabeleceu, por decorrência, gargalos geradores de congestionamento. Adicionalmente, tem-se observado uma piora nos indicadores de cobertura geográfica, com a redução da universalização ao longo do território nacional.

Os problemas podem ser ilustrados da seguinte forma: por conta da maior competitividade no mercado, as companhias aéreas vêm intensificando o uso de sua frota no âmbito de suas redes de operação, visando ganhos de produtividade; igualmente, vêm ampliando sua capacidade produtiva (aeronaves e frequências de vôo) como forma de atender a uma demanda crescente. A forma como o uso da capacidade adicional vem sendo realizado é consistente com a racionalidade de livre mercado: aloca-se número cada vez maior de vôos nas rotas onde as firmas detêm habilidade para precificar mais alto e acima do custo marginal. 
O resultado final dessa combinação de fatores é que se tem reforçado o efeito de maior atração de vôos e geração de gargalos, com maior probabilidade de congestionamento, cancelamentos e atrasos. Assim, é natural observar uma concentração de operações em aeroportos centrais e em horários de pico, dado que o poder de mercado nestas situações é mais alto, e dado o reforço alavancado pela invariabilidade da regra de precificação das infraestruturas.

Este trabalho tem por objetivo estudar o mercado aéreo nacional, priorizando o estudo quanto ao número de aeroportos e analisando as características e consequências pós desregulamentação. Serão utilizados conceitos da econometria, onde, à luz do processo gerador de dados, será criado um modelo que tem o número de aeroportos como variável dependente e o PIB, a taxa de câmbio, tamanho de aeronaves, índices de concentração de aeronaves em aeroportos, número de companhias aéreas, frequência das aeronaves e o yield doméstico como variáveis independentes. Este modelo confirma que as medidas de liberalização do setor aéreo está ligado aos problemas de infraestrutura aeroportuários, que possibilitaram maior liberdade de decisões por parte das empresas aéreas, as quais priorizam suas operações em determinadas cidades, reduzindo a cobertura e causando os gargalos existentes atualmente no setor aeroviário nacional.

Este artigo está estruturado em cinco seções, além desta introdutória. A segunda seção apresenta o Transporte aéreo no Brasil, suas principais características e particularidades pós desregulamentação. A terceira seção será abordado o estudo econométrico, e está dividido em duas sub-seções que são, a apresentação da base de dados e o estudo econométrico. Por fim, a seção final apresentará as conclusões deste trabalho.

\section{A Vulnerabilidade Econômica do Transporte Aéreo Brasileiro}

O setor de transporte aéreo doméstico de passageiros no Brasil apresenta uma particularidade econômica importante, cuja identificação permite maior entendimento das questões que afetam a conjuntura desta indústria e dos setores relacionados: a alternância entre crescimento e crise das operadoras. De fato, o que se vem observando ao longo das décadas é um setor cujo desempenho é extremamente vulnerável a condições exógenas que ora induzem as companhias aéreas para um estado com operações rentáveis, de maior aproveitamento de vôo, 
e gerando inclusive gargalos que sinalizam a necessidade de ampliação de frota e forte utilização da infraestrutura aeroportuária e do espaço aéreo, e ora empurram as mesmas para situações de baixa demanda, excesso de capacidade, pressão em custos, e até estados préfalimentares.

Na figura 1 abaixo pode-se perceber o crescimento da demanda de transporte aéreo no Brasil. De acordo com estudos realizados, o modelo de transporte aéreo mundial terá aumento anual de 5,0\% nos próximos anos. O que pode ser observado na figura 1, é que a demanda por transporte aéreo no Brasil vem crescendo a taxas consideráveis se comparada com índices mundiais, ou seja, o crescimento nos últimos anos apresenta uma média de $12 \%$ ao ano.

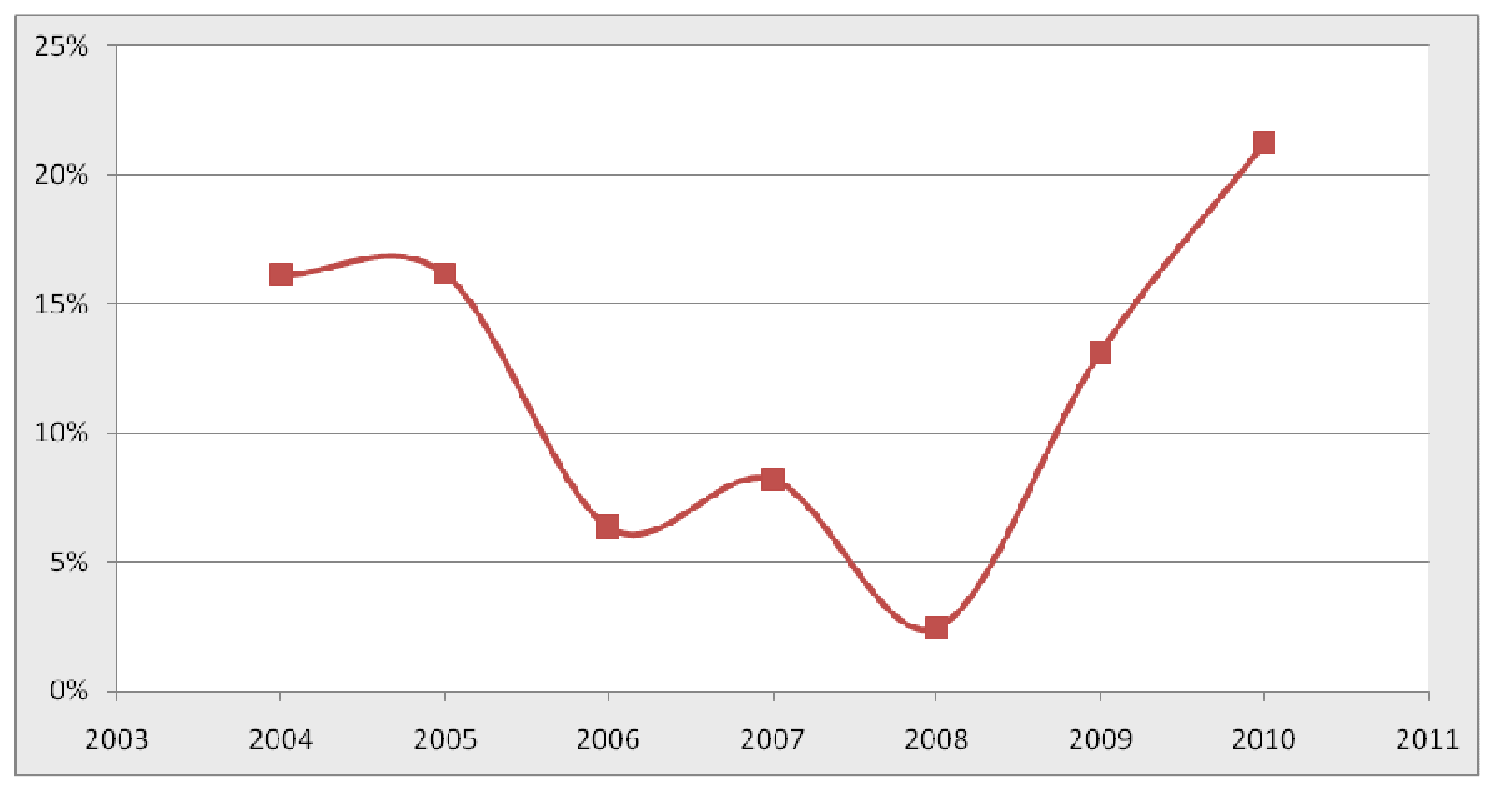

Fonte: INFRAERO 2010

Figura 1 - Taxa de Crescimento anual da demanda do Transporte Aéreo Nacional

Pode-se perceber na figura 1, uma diminuição no crescimento da demanda entre 2006 e 2008, apresentando novamente um crescimento considerável a partir de 2008, permanecendo positivas se considerarmos todo o período analisado. As explicações para a forte vulnerabilidade a choques exógenos desta indústria são conhecidas e em geral, de natureza macroeconômica: pelo lado da procura, tem-se que, por ser um bem com demanda derivada, o montante de tráfego no setor aéreo flutua ao sabor da economia e das expectativas com relação à mesma. E como a própria economia do País é sujeita a episódios de aceleração e desaceleração, tem-se não ser raro observar, no setor aéreo, períodos de bonança, com rápida expansão da oferta, seguidos a períodos de relativa ociosidade. 
Igualmente importantes são os choques causados por desvalorizações cambiais. De fato, temse que variações na taxa de câmbio representam reconhecidos deslocadores de custos no setor, dado ser considerável a parcela de insumos com característica de bens transacionáveis, tradable, como por exemplo, aeronaves, partes de manutenção e combustível. Assim, tem-se que flutuações cambiais afetam diretamente o desempenho do setor aéreo, pelo lado dos custos e comprimindo margens de lucro de maneira quase que instantânea. A precificação no setor também é, em geral, bastante afetada, havendo impactos no crescimento setorial.

No que tange à regulação econômica, as tendências das políticas setoriais no Brasil eram, no final da década de 90, de desregulação, em um arcabouço para se permitir que as operadoras detenham liberdade de controle de suas variáveis estratégicas (preços, entrada, tamanho e formato da operação, tipo de equipamento utilizado e cobertura da malha). O que aconteceu no País ao longo do início dos anos 2000, entretanto, foi uma instabilidade associada à regulação. De fato, observou-se, ao longo desse período, a existência de oscilações nas políticas quanto à intensidade da liberdade permitida às firmas, o que se configurou no chamado "risco regulatório" desta indústria. Este fator contribui para a instabilidade associada ao transporte aéreo no Brasil naquele período.

\subsection{Regulação Econômica}

A "Política de Flexibilização" do transporte aéreo brasileiro foi um conjunto de ações governamentais adotadas a partir do início dos anos 1990 com o objetivo de gradativamente remover os controles do governo sobre variáveis econômicas do setor. Trata-se de um período onde governo e agentes setoriais estavam nitidamente influenciados pelo fortalecimento do ideal do neoliberalismo em nível mundial, bem como pelas percepções quanto aos efeitos que as restrições da política de regulação estrita então vigente acarretavam na dinâmica do mercado.

A Política de Flexibilização do setor começou efetivamente a partir de 1992, dentro do chamado "Programa Federal de Desregulamentação" do Governo Collor (Decreto 99.179, de 15 de março de 1990), apesar de elementos de liberalização de preços por meio de bandas tarifárias já estarem vigentes desde 1989. A liberalização do setor aconteceu de forma gradual, e nas linhas do programa governamental de desregulamentação dos setores regulados 
e da própria economia brasileira. Pode-se dizer que foi implementada em três rodadas, respectivamente, em 1992, 1998 e 2001.

Com a Primeira Rodada de Liberalização, PRL, (1991-1997), os monopólios regionais, vigentes desde a época do SITAR - Sistema Integrado de Transporte Aéreo Regional, foram definitivamente abolidos. No final dos anos 1990, as autoridades de aviação decidiram remover dois importantes dispositivos de controle da competição que ainda perduravam no setor: as bandas tarifárias e a exclusividade do direito de as regionais operarem as Linhas Aéreas Especiais. Isso gerou a Segunda Rodada de Liberalização, SRL, que visava dar mais liberdade às companhias aéreas e que, em última instância, estimulou o primeiro grande surto de competitividade desde o início da desregulamentação. De fato, em 1998, foram observados fenômenos de "guerras de preços" e "corridas por freqüência", que nada mais representavam que os efeitos de curto prazo das novas medidas implementadas, mas que geraram uma movimentação competitiva como não se via pelo menos desde a década de 1960.

Em 2001, um acordo entre o DAC e o Ministério da Fazenda, permitiu que a maioria dos mecanismos de regulação econômica que ainda persistiam no setor, fosse removida, sobretudo com relação ao controle de reajustes de preços de setores regulados que ainda vigia desde a implantação do Plano Real. De fato, por meio de portarias paralelas dos dois órgãos governamentais, foi posta em prática uma total liberalização dos preços. Isso coincidiu com a flexibilização dos processos de entrada de novas firmas e de pedidos de novas linhas aéreas, freqüências de vôo e aviões (Terceira Rodada de Liberalização, TRL, ou "QuaseDesregulação"), em um processo que culminou com a entrada da Gol, em janeiro de 2001.

Finalmente, em 2003, com o novo governo federal, e seguindo novas orientações de política setorial, o regulador voltou a implementar alguns procedimentos de interferência econômica no mercado, objetivando controlar o que foi chamado de "excesso de capacidade" e o acirramento da "competição ruinosa" no mercado.

Pelo texto das portarias de 2003, sobretudo a 243/GC5 (que explicitamente "dispõe sobre as medidas destinadas a promover a adequação da indústria de transporte aéreo à realidade do mercado"), o DAC passa a exercer uma função moderadora, de "adequar a oferta de transporte aéreo, feita pelas empresas aéreas, à evolução da demanda", com a "finalidade de 
impedir uma competição danosa e irracional, com práticas predatórias de conseqüências indesejáveis sobre todas as empresas".

Esse período pode ser denominado de "Re-regulação", uma fase onde pedidos de importação de novas aeronaves, novas linhas e mesmo de entrada de novas companhias aéreas, voltaram a exigir estudos de viabilidade econômica prévia, configurando-se uma situação semelhante ao do período regulatório típico, de controle de oferta. A diferença entre os períodos foi que, desta vez, a autoridade preferiu a utilização de mecanismos discricionários de controle, ao invés de uso de regras explícitas de regulação; isto porque as portarias não previam exatamente quando estariam dadas as condições para que o regulador utilizasse seus poderes de arrefecimento da competição via congelamento de oferta - deixando a questão para a livre interpretação do próprio regulador.

\subsection{Problemática Recente: Concentração e Deterioração da Cobertura}

Há evidências que a Política de Flexibilização gerou ganhos indubitáveis ao setor aéreo no Brasil, com queda de preços, maior eficiência operacional e competitividade das empresas. Mais do que isso, e semelhante ao que aconteceu nos Estados Unidos e por toda parte ao redor do mundo onde houve liberalização econômica da aviação, observou-se uma visível expansão do setor, com um número maior de viagens por parte dos atuais consumidores e acessibilidade de novos segmentos de consumidores - aqueles passageiros que viajam pela primeira vez no modal aéreo.

Por outro lado, entretanto, e em paralelo ao debate acerca da maior ou menor liberdade estratégica permitida pelo atual marco regulatório do transporte aéreo brasileiro, uma questão que envolve regulação do setor aéreo e das infraestruturas associadas e, ao mesmo tempo, diz respeito a indicadores sociais referentes ao setor, tornou-se premente nos últimos anos: a deterioração da cobertura dos serviços aéreos ao longo do território nacional e consequente concentração em poucos aeroportos.

Para se ter uma idéia do processo de deterioração da cobertura do transporte aéreo no País, tem-se a Figura 2, que apresenta a evolução, em termos percentuais, da participação dos quinze maiores aeroportos brasileiros (chamados de "Top-15") no total de frequências de vôos no segmento regular doméstico de passageiros no início dos anos 2000: 


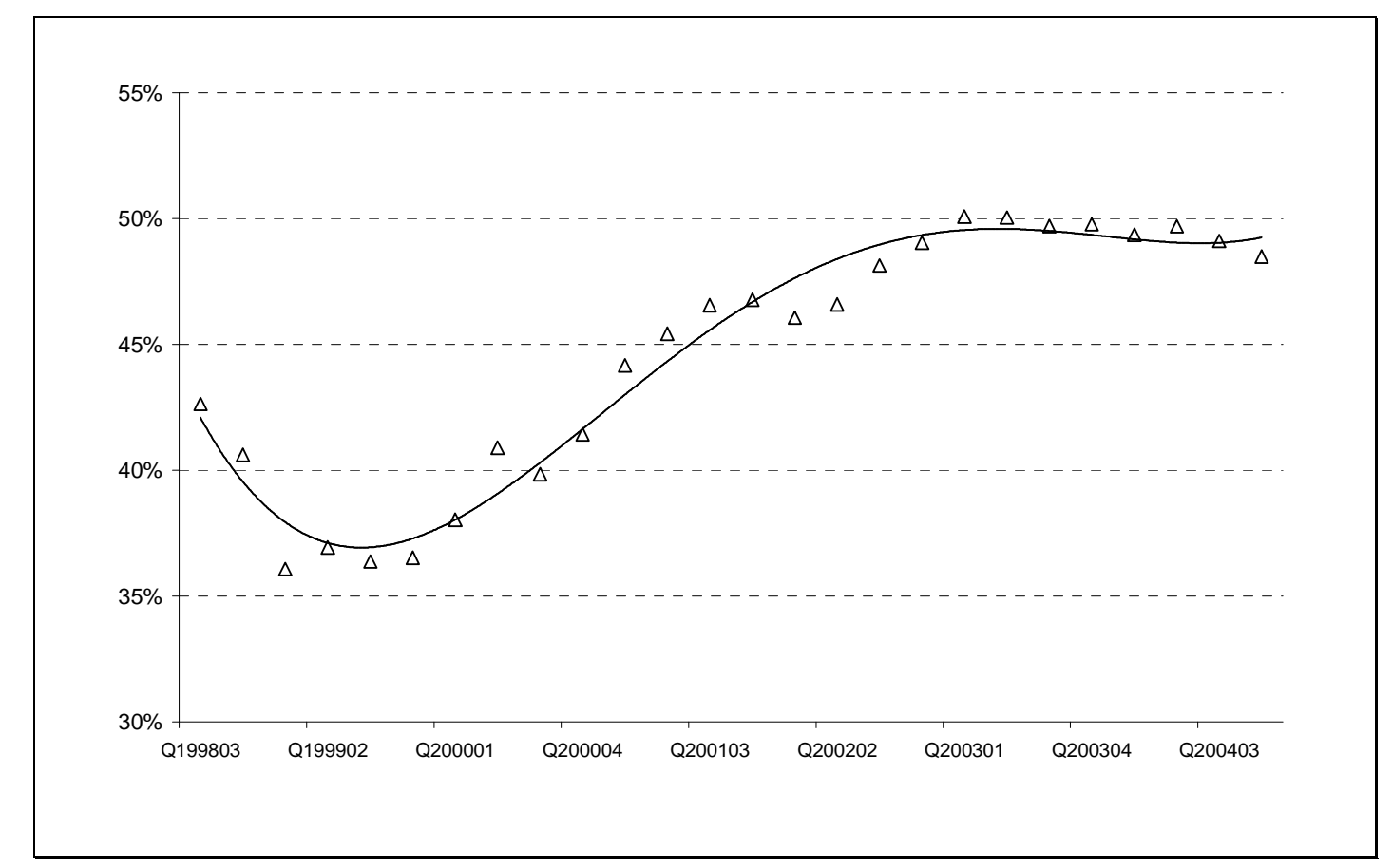

Fonte: Sistema BAV/HOTRAN - Departamento de Aviação Civil

Figura 2 - Evolução da Concentração das Freqüiências Domésticas nos Aeroportos Top-15

Pode-se perceber, por meio da Figura 3, que desde o final de 2000, tem havido, por parte das companhias aéreas, um movimento de concentração dos vôos regulares nos quinze maiores aeroportos brasileiros em detrimento dos aeroportos de pequeno em menor porte. De fato, tem-se que a fatia de mercado dos quinze principais aeroportos subiu de valores em torno de $35-40 \%$ para $50 \%$.

Somadas, as demandas dos 15 aeroportos chegam a 83\% da demanda total do país. Essa demanda se explica pela concentração expressiva de voos nesses aeroportos. Percebe-se uma concentração nos Top-5 de 49\% do total de passageiros do país. Juntos, os aeroportos de São Paulo (Guarulhos e Congonhas) concentram 27\%, seguidos pelo aeroporto de Brasília, com $9 \%$, e Galeão e Vitória, com 8 e 5\%, respectivamente. 


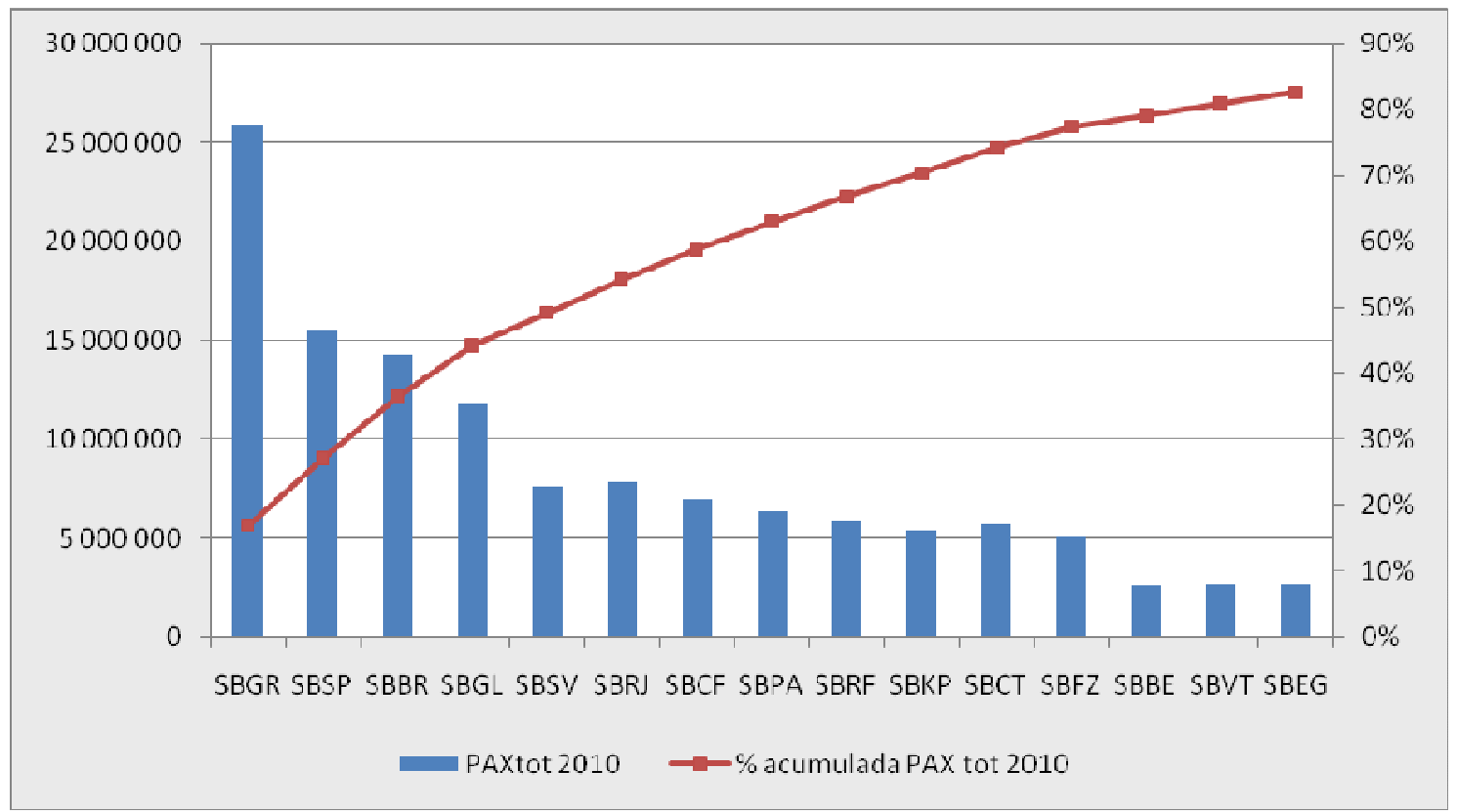

\section{Fonte: INFRAERO 2010}

Figura 3 - Demanda nos Aeroportos Top-15

Este problema de tendência à concentração das vôos em grandes aeroportos pode ser indicativo de uma estratégia de "hubinização" das malhas das companhias aéreas. A hubinização diz respeito à configuração das redes no formato hub-and-spoke, padrão de malha amplamente adotado nos Estados Unidos no período imediatamente posterior à desregulamentação econômica de 1978. Este movimento representaria uma decorrência natural da busca de maior eficiência econômica por parte das companhias aéreas em um mercado livre - o que, indubitavelmente, representa um ganho para as companhias aéreas e não, necessariamente, para o setor. Por conta da maior competitividade no mercado, as companhias aéreas intensificam o uso de sua frota no âmbito de suas redes de operação, visando ganhos de produtividade; igualmente, ampliam sua capacidade produtiva instalada, em termos de número e tamanho de aeronaves e de frequiências de vôo, como forma de atender à demanda crescente por transporte aéreo.

Por outro lado, é importante salientar que a concentração geográfica da aviação comercial representa uma nítida piora em importantes indicadores sociais, no que tange à universalização do mesmo: com uma pior cobertura ao longo do território nacional, menor a universalidade do setor, e menor o bem-estar associado. 
Com relação à universalização, um dos indicadores mais comumente utilizado é o número de de aeroportos que servem o modal. Este indicador possibilita uma visão rápida e clara da evolução da cobertura geográfica da aviação comercial.

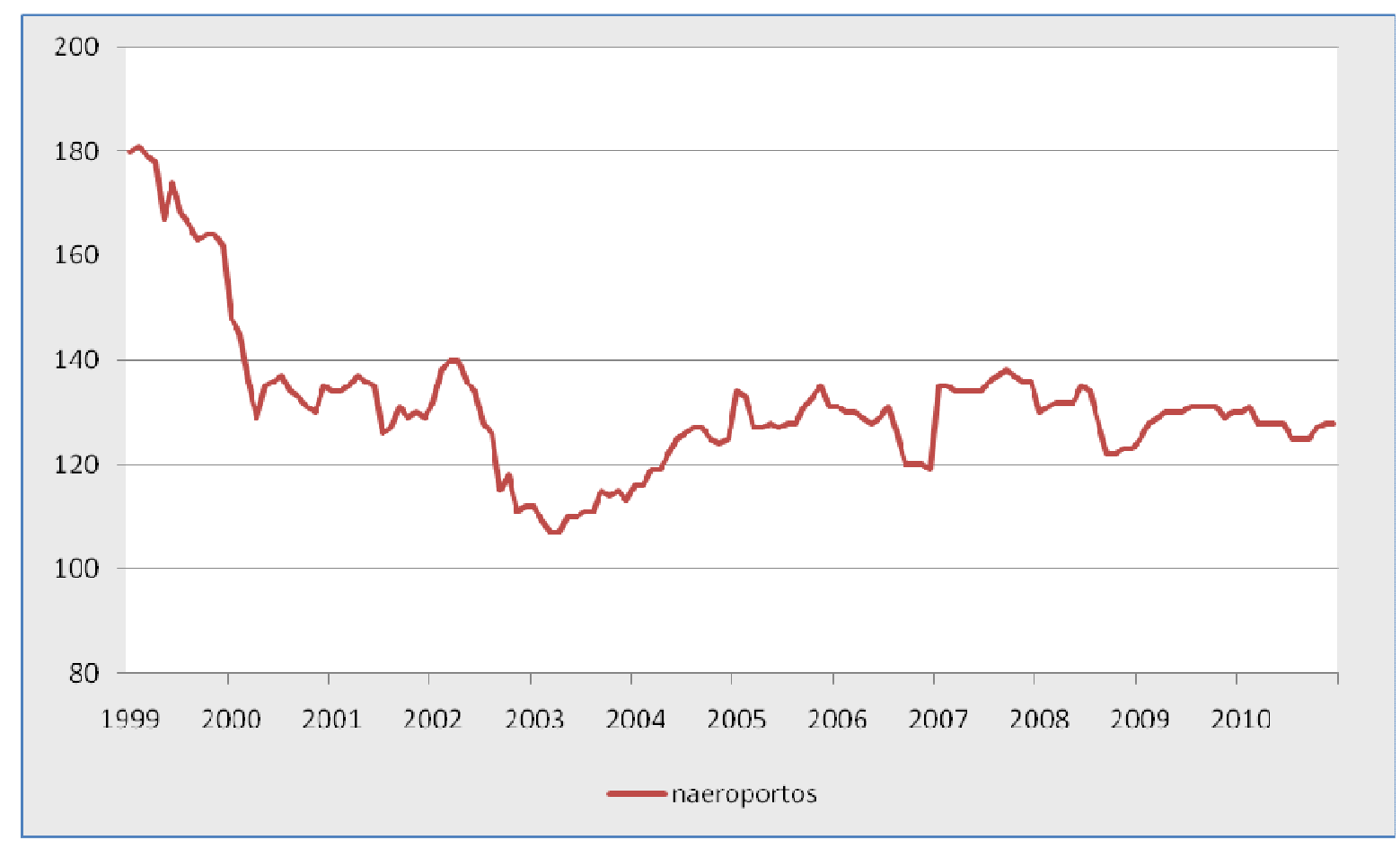

Fonte: Departamento de Aviação Civil

Figura 4 - Número de Aeroportos - Transporte Aéreo Regular

Historicamente, tem-se que o transporte aéreo regular no Brasil já alcançou, no passado, uma cobertura de mais de 300 cidades ao longo do território. Esta situação foi rapidamente deteriorada ao longo dos anos 1960. Aeronaves mais modernas e maiores introduzidas no mercado podem ter contribuido para a mudança da malha aérea. Como consequência, houve uma maior concentração nas cidades de maior expansão econômica, limitando o número de cidades servidas por aeroportos.

Como se pode constatar pela Figura 4, até 2003 o País apresentou uma situação de piora da universalização - desta vez sob um regime de liberdade estratégicas das empresas. Um fator explicativo adicional para isso é a forte variabilidade nas taxas de câmbio no setor. Como vimos, o câmbio, por ser um importante deslocador de custos das companhias aéreas (devido a combustível, arrendamento de aeronaves, peças para manutenção, etc.), configura-se também como um deslocador da oferta de vôos das companhias aéreas e, inclusive, da oferta de serviço para as localidades cuja densidade é mais reduzida. Percebe-se, a partir dai, que o 
número de aeroportos se mantém entre 120 e 140. Com o incremento na concentração e, provavelmente, com as estratégias visando a maior "hubinização" das redes, vem-se observando um movimento de queda acentuada na cobertura no período recente.

\section{Estudo do número de aeroportos brasileiros}

Para analisar a relação existente entre as variáveis selecionadas e o número de aeroportos brasileiros, foi feita uma análise qualitativa e quantitativa da base de dados, com o desenvolvimento de modelos econométricos.

\subsection{Apresentação da Base de Dados}

A base de dados utilizada provém de dados fornecidos pela ANAC (Agência Nacional de Aviação Civil) e pela INFRAERO (Empresa Brasileira de Infraestrutura Aeroportuária). As variáveis utilizadas e analisadas foram o número de aeroportos no território nacional (naeroportos), o Produto Interno Bruto (PIB), a taxa de câmbio (usd), custo médio do querosene de aviação - qav (cme_qav), tamanho médio das aeronaves na aviação regular doméstica (tamav), total de frequências das aeronaves na aviação regular doméstica (freqtot), índice de concentração de frequências em aeroportos das aeronaves na aviação regular doméstica (hhifr), número de companhias aéreas na aviação regular doméstica (ncias), etapa média de companhias aéreas na aviação regular doméstica (avstl) e yield médio doméstico nominal (yielddom), sendo o yield valor médio pago por quilômetro voado. Umas das variáveis binárias adicionadas ao modelo foi a dummy "dcazul", representando a entrada da empresa que impactou o mercado introduzindo aeronaves menores e acirrando a competividade entre as companhias existentes, além das variáveis de sazonalidade (m_i).

Abaixo serão explicadas com mais detalhes as séries que foram consideradas.

- Número de aeroportos (naeroportos): número de aeroportos servidos pela aviação regular. Esses dados foram coletados junto a base de dados da ANAC/HOTRAN. A série fornece dados mensais, entre janeiro de 1999 e dezembro de 2010. 
- Produto Interno Bruto (PIB): dados obtidos junto ao Banco Central do Brasil. Acredita-se que esta variável tem grande correlação com a demanda nacional e, portanto, pode estar relacionada ao número de aeroportos.

- Taxa de câmbio (usd): taxa de câmbio obtido junto ao Banco Central do Brasil. Esta variável foi inserida para verificar sua correlação com o número de aeroportos, que possívelmente interfere no custo do qav e, consequentemente, nos preços cobrados pelas empresas aéreas.

- Custo médio do querosene de aviação (cme_qav): custo médio do qav é obtido junto a ANAC e DAC, diretamente relacionado com os preços cobrados pelas empresas aéreas.

- Tamanho médio das aeronaves na aviação regular doméstica (tamav): Dados coletados junto a base de dados da ANAC/HOTRAN. Acredita-se que esta variável tem correlação inversa com o número de aeroportos.

- Frequências das aeronaves na aviação regular doméstica (freqtot): Dados coletados junto a base de dados da ANAC/HOTRAN. Esta variável foi inserida no modelo para análise de correlação entre o número de aeroportos e concentração dos mesmos.

- Índice de concentração de frequências das aeronaves em aeroportos na aviação regular doméstica (hhifr): O índice é um HHI - Herfindhal-Hirschman, visando indicar a concentração com relação a aeroportos. Quanto mais frequências de voos em poucos aeroportos, mais concentrados serão os aeroportos.

- Número de companhias aéreas (ncias): Dados coletados junto a base de dados da ANAC/HOTRAN.

- Etapa média (avstl): Dados coletados junto a base de dados da ANAC/HOTRAN. Esta variável representa a etapa média realizada pelas empresas aéreas.

- Yield doméstico nominal (yielddom): yield é valor médio pago por quilômetro voado. Dados coletados junto a base de dados da ANAC.

Através da Tabela 1, tem-se as estatísticas descritivas das variáveis consideradas. 
Tabela 1 - Resumo das variáveis analisadas

\begin{tabular}{lccccc}
\hline \hline Variable & Obs & Mean & Std. Dev. & Min & Max \\
\hline \hline naeroportos & 144 & 131.4167 & 14.20701 & 107 & 181 \\
pib & 144 & 245.5471 & 43.67452 & 176.4235 & 351.111 \\
usd & 144 & 3.40317 & 1.116519 & 1.758307 & 6.558112 \\
cme_qav & 144 & 1.524073 & .5095093 & .447658 & 3.739413 \\
tamav & 144 & 119.2091 & 16.84513 & 84.02455 & 146.5792 \\
freqtot & 144 & 10152.34 & 4128.471 & 6577 & 28191 \\
hhifr & 144 & .2070368 & .0538705 & .094742 & .294211 \\
ncias & 144 & 17.74306 & 1.815807 & 15 & 21 \\
avstl & 144 & 657.2378 & 86.53287 & 540.2178 & 859.9236 \\
yielddom & 144 & .6209642 & .1886603 & .3097044 & 1.033171 \\
dcazul & 145 & .1793103 & .3849417 & 0 & 1 \\
\hline & & & & & \\
\hline
\end{tabular}

Tabela 2 - Matriz de correlações

\begin{tabular}{|c|c|c|c|c|c|c|c|c|c|c|c|}
\hline & naeroportos & pib & usd & cme_qav & tamav & freqtot & hhifr & ncias & avstl & yielddom & dcazul \\
\hline naeroportos & 1.0000 & & & & & & & & & & \\
\hline Pib & -0.2734 & 1.0000 & & & & & & & & & \\
\hline Usd & -0.0934 & -0.8093 & 1.0000 & & & & & & & & \\
\hline cme_qav & -0.5591 & 0.5881 & -0.4104 & 1.0000 & & & & & & & \\
\hline Tamav & -0.5392 & 0.8776 & -0.6636 & 0.7446 & 1.0000 & & & & & & \\
\hline Freqtot & 0.0303 & 0.5634 & -0.4742 & 0.0413 & 0.4081 & 1.0000 & & & & & \\
\hline Hhifr & -0.5040 & 0.7692 & -0.5863 & 0.6797 & 0.9186 & 0.3007 & 1.0000 & & & & \\
\hline Ncias & 0.5978 & -0.1013 & -0.3293 & -0.2191 & -0.2018 & -0.1882 & -0.1021 & 1.0000 & & & \\
\hline Avstl & -0.2970 & 0.9459 & -0.8190 & 0.5698 & 0.9199 & 0.6354 & 0.8110 & -0.0676 & 1.0000 & & \\
\hline yielddom & -0.5553 & -0.0911 & 0.3316 & 0.4191 & 0.2407 & -0.4445 & 0.2130 & -0.3674 & -0.0861 & 1.0000 & \\
\hline Dcazul & -0.0990 & 0.6755 & -0.5449 & 0.1249 & 0.5115 & 0.8051 & 0.3383 & -0.3199 & 0.7000 & -0.3911 & 1.0000 \\
\hline
\end{tabular}

A Tabela 2 apresenta a matriz de correlação das variáveis estudadas. Observa-se que o número de aeroportos é positivamente correlacionado com o número de companhias aéreas e com a frequência total das aeronaves na aviação civil, ou seja, quanto maior o número de companhias aéreas ou quanto maior a frequência de voos, o número de aeroportos deve aumentar. Inversamente proporcionais estão a taxa de câmbio e o custo de querosene para aviação. Estas variáveis representam os custos para o setor que, aparentemente, geram uma maior pressão para que alguns aeroportos sejam cortados das malhas aéreas. 


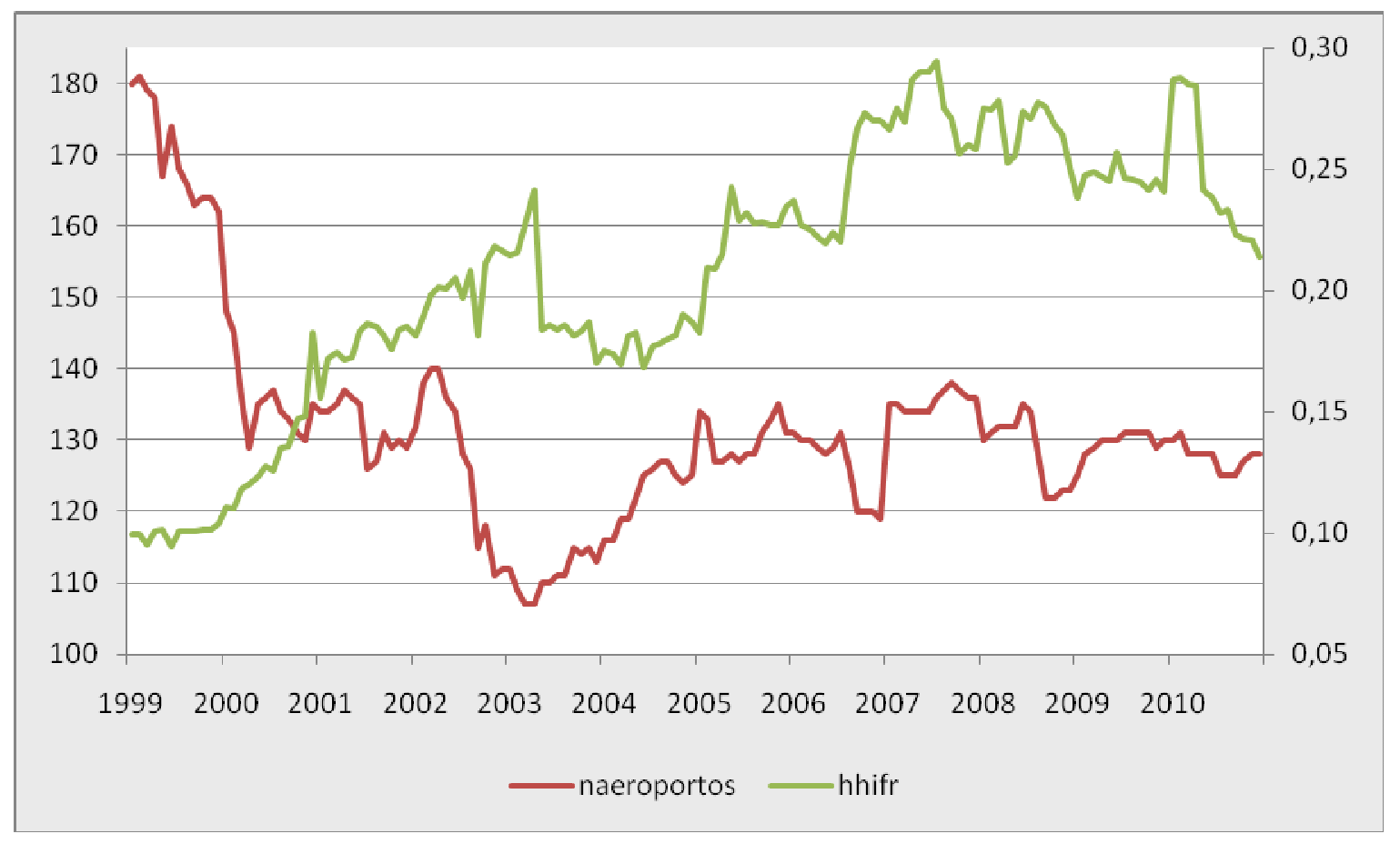

Figura 5 - Relações entre o número de aeroportos e hhifr

Na Figura 5, pode-se analisar relação entre o índice de concentração de frequências das aeronaves e o número de aeroportos servidos pela aviação regular. Percebe-se claramente, a partir do gráfico, a relação inversamente proporcional das variáveis até 2003, ou seja, com o aumento do índice de concentração de frequências das aeronaves há um decréscimo no número de aeroportos. Pode-se observar que a partir de 2003, fatores externos podem ter interferido na correlação entre essas variáveis, como por exemplo, o aumento da demanda. $\mathrm{O}$ aumento da demana, representada neste modelo pelo PIB, está diretamente correlacionado com o número de aeroportos. Havendo um aumento na demanda, consequentemente deveríamos ter um aumento no número de aeroportos. Como isso normalmente não ocorre, como consequência tem-se o aumento da concentração nos aeroportos existentes.

\subsection{Estudo Econométrico e Análise de Resultados}

O modelo econométrico foi definido à partir da análise das variáveis anteriormente citadas, objetivando a escolha de um modelo que melhor represente o número de aeroportos em função dessas variáveis. 
Foram estudados três tipos de especificações de regressão múltipla, a primeira opção com a variável dependente e as variáveis independentes lineares (lin_lin), a segunda com a base logarítmica em ambas as variáveis (log_log) e por último, um modelo misto, variável dependente na base logarítimica e as variáveis independentes lineares (log_lin). Considerouse o número de aeroportos como variável dependente ( $\mathrm{y}=$ naeroportos), as variáveis independentes são o PIB (pib), a taxa de câmbio (usd), o tamanho das aeronaves (tamav), frequência das aeronaves (freqtot), HHI (índice de concentração) de frequências das aeronaves nos aeroportos (hhifr), yield doméstico (yielddom), além da variável dummy dcazul, com o intuito de controlar os efeitos da entrada dessa empressa no cenário nacional a partir de 2009, e as variáveis meses para controlar efeitos da sazonalidade (m_i).

As análises foram feitas para os três modelos e ao final foi escolhido um modelo campeão. A escolha foi baseada na significância estatística das variáveis consideradas, bem como na qualidade do ajuste verificado através do R-quadrado $\left(R^{2}\right)$. A função estabelecida para o número de aeroportos pode ser escrita da seguinte forma :

$$
\begin{aligned}
& \ln \text { naeroportos }=\beta_{0}+\beta_{1} \text { pib }+\beta_{2} \text { usd }+\beta_{3} \text { tamav }+ \\
& \beta_{4} \text { freqtot }+\beta_{5} \text { hhifr }+\beta_{6} \text { ncias }+\beta_{7} \text { yielddom }+\beta_{8} \text { dcazul }+\sum_{i=1}^{12} \beta_{i} m_{-} i
\end{aligned}
$$

O resumo dos resultados dos modelos analisados pode ser visto na tabela 4 .

Ao se comparar o modelo completo e modelos com subespecificados, ou seja, com alternância das variáveis analisadas, obtem-se os seguintes resultados, conforme a Tabela 4. Observa-se que o modelo completo é o que apresenta o maior número de variáveis estatisticamente significantes, além de apresentar o maior $\mathrm{R}^{2}$. Eliminando as variáveis do tamanho das aeronaves (b), freqtot (c), número de companhias aéreas (d) e yielddom (e), verifica-se uma diminuição no $\mathrm{R}^{2}$, o que representa que essas variáveis têm significância no modelo. 
Tabela 4 - Comparação entre diferentes especificações

\begin{tabular}{|c|c|c|c|c|c|}
\hline Variable & completo & $\mathbf{b}$ & c & d & e \\
\hline pib & $.0015^{* *}$ & -.00021 & $.00164 * *$ & .00114 & $.00117 *$ \\
\hline usd & $-.0329 * *$ & -.0261 & $-.0297 *$ & $-.065 * * *$ & $-.0296 *$ \\
\hline tamav & $-.00921 * * *$ & & $-.00925 * * *$ & $-.0092 * * *$ & $-.007 * * *$ \\
\hline freqtot & $4.3 \mathrm{e}-06^{* * *}$ & $4.5 \mathrm{e}-06^{* *}$ & & $4.3 \mathrm{e}-06^{* *}$ & $3.5 \mathrm{e}-06 * *$ \\
\hline hhifr & .255 & $-.959 * * *$ & .27 & .24 & .0257 \\
\hline ncias & $.0213 * * *$ & $.0213 * *$ & $.0214 * * *$ & & $.0182 * * *$ \\
\hline yielddom & $.115^{* *}$ & $-.107 *$ & .0931 & .0393 & \\
\hline dcazul & .0232 & -.0294 & $.0518 *$ & -.047 & -.00507 \\
\hline $\mathrm{m} \_1$ & $.0411^{* *}$ & .00544 & $.0486 * *$ & .0377 & $.0336^{*}$ \\
\hline $\mathrm{m} \_2$ & $.0609 * *$ & .00904 & $.0664 * *$ & $.0612 *$ & $.0496 *$ \\
\hline m_3 & $.0444 *$ & .00649 & $.0514 * *$ & .0373 & .034 \\
\hline $\mathrm{m} \_4$ & .0367 & .00282 & $.0436 *$ & .0269 & .0274 \\
\hline m_5 & .0213 & .00302 & .022 & .0173 & .0144 \\
\hline m_6 & .0272 & .0107 & .0276 & .0242 & .0201 \\
\hline m_7 & .024 & .00935 & .0248 & .0203 & .0194 \\
\hline $\mathrm{m} \_8$ & .0109 & .00839 & .0106 & .00817 & .00914 \\
\hline m_9 & .0262 & -.00251 & .0247 & .0165 & .0162 \\
\hline $\mathrm{m} \_10$ & .00346 & .00553 & .00382 & .00175 & .00203 \\
\hline $\mathrm{m} \_11$ & -.00269 & .00258 & -.0035 & -.00587 & -.00418 \\
\hline r2_a & .708 & .622 & .7 & .661 & 699 \\
\hline
\end{tabular}

legenda: $*$ p-valor $<0.1 ; * *$ p-valor $<0.05 ; * * *$ p-valor $<0.01$

Podemos perceber que as variáveis do pib, usd, tamav, freqtot, ncias e yielddom são estatisticamente significantes a 5\%, ou seja, com evidências de causalidade sobre o número de aeroportos. Neste modelo, o PIB representa a demanda doméstica nacional, e com sinal positivo que indica um aumento no número de aeroportos com o aumento do PIB. O sinal negativo para as variáveis usd e tamav representam uma diminuição no número de aeroportos com o aumento aumento dessas variáveis. $\mathrm{O}$ aumento da taxa de câmbio faz com que as empresas tenham suas despesas aumentadas, gerando maior pressão dos custos, o que aparentemente faz com que aeroportos sejam "cortados" das malhas das aéreas. O Índice de concentração de frequências das aeronaves em aeroportos (hhifr) não apresentou resultados estatisticamente significantes, provavelmente por haver correlação com outras variáveis envolvidas no modelo. Porém, com valores positivos para o hhifr teriamos que um aumento dessa variável refletiria no aumento do número de aeroportos, isso porém não é verificado, conforme apresentado na Figura 5. Temos então uma menor cobertura geográfica e um aumento da concentração de aeronaves em poucos aeroportos, que por consequência causam gargalos, atrasos e prejuízos para os passageiros. 
O modelo completo log-lin apresenta o maior $\mathrm{R}^{2}(0,708)$, ou seja, apresenta melhor qualidade de ajuste, e suas variáveis são mais significantes estatisticamente do que no modelo lin-lin (valor-P menor), razão da escolha. Quanto à análise das elasticidades, conforme Tabela 5 abaixo, relacionando o número de aeroportos com as variáveis análisadas, tem-se que para um aumento de $1 \%$ no PIB, ter-se-á um aumento de $0,36 \%$ no número de aeroportos. Esse mesmo aumento acontecerá se considerando um aumento de $1 \%$ no número de companhias aéreas. Nota-se que um aumento de $1 \%$ na taxa de câmbio ou no tamanho das aeronaves, o número de aeroportos diminuirá em 0,11 e 1,09\%, respectivamente. Por fim, o Índice de concentração de frequências das aeronaves em aeroportos na aviação regular doméstica (hhifr) apresentou um P-valor de 0,528 (conforme Tabela 5), porém o episódio inicial de aumento da concentração com queda no número de aeroportos reforça a suspeita de que sejam correlacionadas.

Tabela 5 - Elasticidade modelo log-lin

$$
\begin{aligned}
& \text { Elasticities after ivreg29 } \\
& \qquad \begin{aligned}
\mathrm{y} & =\text { Linear prediction predict) } \\
& =4.8730527
\end{aligned}
\end{aligned}
$$

\begin{tabular}{lccccccc}
\hline \hline variable & $\mathbf{d y} / \mathbf{e x}$ & Std. Err. & $\mathbf{z}$ & $\mathbf{P}>\mathbf{z}$ & [ $\mathbf{9 5 \%}$ & C.I. $]$ & $\mathbf{X}$ \\
\hline \hline pib & .3685826 & .1545 & 2.39 & 0.017 & .065774 & .671392 & 245.547 \\
usd & -.1120917 & .05289 & -2.12 & 0.034 & -.215746 & -.008438 & 3.40317 \\
tamav & -1.097584 & .26916 & -4.08 & 0.000 & -1.62512 & -.570046 & 119.209 \\
freqtot & .0439828 & .0162 & 2.72 & 0.007 & .012241 & .075725 & 10152.3 \\
hhifr & .0528886 & .08373 & 0.63 & 0.528 & -.111218 & .216995 & .207037 \\
ncias & .3786111 & .12748 & 2.97 & 0.003 & .128762 & .62846 & 17.7431 \\
yielddom & .0713068 & .03495 & 2.04 & 0.041 & .002802 & .139811 & .620964 \\
dcazul & .0040332 & .00601 & 0.67 & 0.502 & -.007738 & .015805 & .173611 \\
\hline
\end{tabular}

\section{Conclusões}

Como apontado durante o trabalho, o transporte aéreo regular do país apresentou um crescimento considerável nos últimos anos. Este crescimento está relacionado com fatores econômicos e de desenvolvimento nacional, bem como às políticas de regulamentação do setor aéreo nacional. A desregulamentação propiciou o gerenciamento de tarifas e rotas pelas empresas aéreas, aumento da concorrência entre essas empresas. O país possui hoje um transporte aéreo mais competitivo e eficiente, mas também com operação mais concentrada em poucos aeroportos e regiões. 
Para a realização deste trabalho foram analisadas as variáveis que se acredita estarem envolvidas na determinação do número de aeroportos. Os modelos econométricos desenvolvidos a partir de dados fornecidos pela ANAC e INFRAERO, resultam em valores estatisticamente significantes a 2 e 5\%. Estas são as variáveis com maior significância na determinação do modelo, ou seja, o PIB, taxa de câmbio, o tamanho das aeronaves, concentração de frequências das aeronaves, o número de companhias aéreas e o yield.

Conforme o modelo desenvolvido, pode-se perceber que, quanto à análise das elasticidades, tem-se que para um aumento de $1 \%$ no PIB ou no número de companhias aéreas, ter-se-á um aumento de $0,36 \%$ no número de aeroportos. Percebe-se, também, que um aumento de $1 \%$ na taxa de câmbio ou no tamanho das aeronaves, o número de aeroportos diminuirá em 0,11 e $1,09 \%$, respectivamente.

A partir deste estudo podemos concluir que o cresimento da demanda de passageiros, representada pelo PIB, aliado a redução do número de aeroportos, faz com que existam concentrações de movimentos de aeronaves em determinadas cidades ditas economicamente mais favoráveis, restringindo o atendimento/acesso à diversas regiões do país, observando-se uma piora nos indicadores de cobertura geográfica, com a redução da universalização ao longo do território nacional. Essa concentração de frequências de voos em determinados aeroportos ocorre em função da maior competitividade no mercado. É fundamental que a gestão aeroportuária seja mais flexível, a ponto de haver concorrência entre aeroportos, bem como e intensificação do uso da tarifação como mecanismo de gerenciamento de demanda.

Um outro aspecto de políticas governamentais que deve ser considerado no setor aéreo e que não necessariamente implica em um revés à liberalização econômica do setor diz respeito ao fomento à aviação regional. O setor vem apresentando quedas significativas nestes importantes indicadores sociais. Há um importante espaço para a construção de políticas industriais que induzam a aviação regional e criem, por exemplo, public-service offers (PSO), buscando o investimento na indução de aeroportos secundários e regionais, de forma a não apenas desconcentrar a operação nos grandes centros, mas de ampliar a acessibilidade do setor. Estas medidas têm potencialidade de induzir um crescimento mais ordenado, sustentável e equânime do transporte aéreo, inclusive com melhoria dos seus indicadores e metas sociais e geográficas. 


\section{Referências}

Alves, C. J. P. e Amaral, F. C. F. (2012) A situação da infraestrutura aeroportuária na região norte e seu potencial apoio à aviação regional. Journal of Transport Literature, vol. 6, n.1.

Bettini, H. F. (2007) Um Retrato da Aviação Regional no Brasil. Journal of Transport Literature, vol. 1, n. 1, pp. 46-65.

Bettini, H. F. A. J. e Oliveira, A. V. M. (2011) Transporte aéreo regional: entre economias de densidade e custos de transação. Journal of Transport Literature, vol. 5, n. 4, pp. 171-187.

Camilo Pereira, A. P. e Silveira, M. R. (2011) Setor aéreo regional no estado de São Paulo: o papel do estado na gestão do transporte aéreo. Journal of Transport Literature, vol. 5, n. 1, pp. 97-123.

Coelho, L. G., Silva, A. N. R. e Dinato, A. C. (2012) Capacidade e nível de serviço do terminal de passageiros de um aeroporto regional - o caso de Ribeirão Preto. Journal of Transport Literature, Vol. 6, n.3.

Costa, T. F. G., Lohmann, G. e Oliveira, A. V. M. (2011). Mensuração de Concentração e Identificação de Hubs no Transporte Aéreo. Journal of Transport Literature, vol. 5, n. 2, pp. 106-133.

Costa, T. F. G., Lohmann, G. e Oliveira, A. V. M. (2010) A Model to Identify Airport Hubs e their Importance to Tourism in Brazil. Research in Transportation Economics, vol. 26, pp. 3-11

Demant, M. A. R. (2011) Infraestrutura aeroportuária e o desenvolvimento do tráfego aéreo regional no Brasil. Journal of Transport Literature, vol. 5, n. 1, pp. 124-160.

Fregnani, J. A., Ferreira, N. S. e Griebeler, M. C. (2009) Análise de Custos Logísticos do Transporte Aéreo Regional. Journal of Transport Literature, vol. 3, n. 2, pp. 7-24.

Oliveira, A. V. M. (2010) A Alocação de Slots em Aeroportos Congestionados e suas Consequências no Poder de Mercado das Companhias Aéreas. Journal of Transport Literature, vol. 4, n. 2, pp. $5-49$.

Rocha, G. C. (2010) Ensaios sobre a Demanda do Transporte Aéreo Regional. Journal of Transport Literature, vol. 4, n. 1, pp. 114-133.

Salgado L. H. (2008) Tópicos sobre regulação na aviação civil, $7^{\circ}$ Simpósio de Transporte Aéreo SITRAER.

Santos, F. A. B. (2009) As Consequências da Desregulamentação Econômica na Indústria do Transporte Aéreo. Journal of Transport Literature, vol. 3, n. 2, pp. 68-79.

Turolla, F. A., Lima, M. F. F. e Ohira, T. H. (2011) Políticas públicas para a melhoria da competitividade da aviação regional brasileira. Journal of Transport Literature, vol. 5, n. 4, pp. 188-231. 